\title{
FROM THE SOCIAL TO THE COMMUNICATIVE CONSTRUCTION OF REALITY
}

\section{FLORIAN ZNANIECKI LECTURE, WARSAW, 12.1.2016}

Hubert Knoblauch

Technische Universität Berlin

\section{/// Introduction}

It is an honour to give a talk in a series named after Florian Znaniecki. Znaniecki is not only a great Polish sociologist. In these troubled times of populist nationalism it is worth mentioning that he too was a refugee, who as an American sociologist and an eminent figure on the global scene eventually became a classic. As Hałas (2010) has shown vividly in various publications, Znaniecki had contributed to the general idea of what sociology is about. For me, personally, the Social Role of the Man of Knowledge (Znaniecki 1975) was his most influential book, as it formulates basic concepts of the sociology of knowledge (Knoblauch 2005).

The sociology of knowledge may also be considered as the starting ground of my presentation. As you may well know, the first book on the social construction of reality by Berger and Luckmann (1966) was subtitled $A$ Treatise in the Sociology of Knowledge. It is, however, not the aspect of knowledge which is the focus of my paper, but rather the idea of the social construction of reality, which gave rise to various academic movements, such as "social constructionism" or "social constructivism". The idea of social construction disseminated into all of the social sciences and the humanities and brought about interdisciplinary fields, such as gender studies. The critique of gender studies, however, also proves to what degree the diffusion of the notion of social construction can be vulgarized and, consequently, can fall prey to neo-realist and neo-conservative critics. As 
"social construction" became a formula, it lost contact with the concept developed in the book ${ }^{1}$. Since the critique of social construction often attacks its misconceptions, it is therefore necessary to reformulate this idea in a way which avoids the confusion with its popularized and vulgarized versions. This reformulation is even more necessary because society has been changing fundamentally. Both reasons account for the argument I want to put forward. Moreover, I want to give two major reasons why we should modify the idea of social construction and move on to communicative constructivism. In the first place, communicative construction allows us to meet recent demands to respect materiality and embodiment in the social sciences, as voiced by practice theory and actor-network theory (ANT). And secondly, it takes account of the fact that society has changed from an industrial one into a knowledge one and now into a communication society.

For the sake of brevity, I have to shorten some of the arguments ${ }^{2}$. Therefore, I want to first remind you of the essential distinction between "constructivism" and its "social" twin before I sketch the basic idea of social construction. I will then turn to some of the critics of social construction before describing the communicative construction approach. I will end with some reflections about its larger societal context, i.e. the communication society.

\section{/// Constructivism and social construction}

If one turns to any subject matter in the social sciences and the humanities, it is highly improbable not to come across the idea of constructivism. There are specific approaches in the political sciences, in Science and Technology Studies, in the study of emotions, social problems or gender. In fact, constructivism has become so ubiquitous that in recent years we have witnessed a rising opposition against its dominance, be it by postconstructivism or neorealism. I will address some of the critical arguments later. Before we turn to some of those claims, we have to address one basic misunderstanding. It concerns the assumption that constructivism and the idea of social construction are virtually identical. Thus, in his famous article on constructivism, Michael Lynch (1998) traces the "genealogy" of con-

\footnotetext{
${ }^{1}$ For a more extended analysis of the reception of the Social Construction of Reality, the pattern of its diffusion and its relation to "constructivism" see Knoblauch, Wilke 2016.

${ }^{2}$ For some sketches on communicative constructivism see Knoblauch (2013; 2016); a more extensive treatise on the Communicative Construction of Reality (Die kommunikative Konstruktion der Wirklichkeit) (2017); an English version is in preparation.
} 


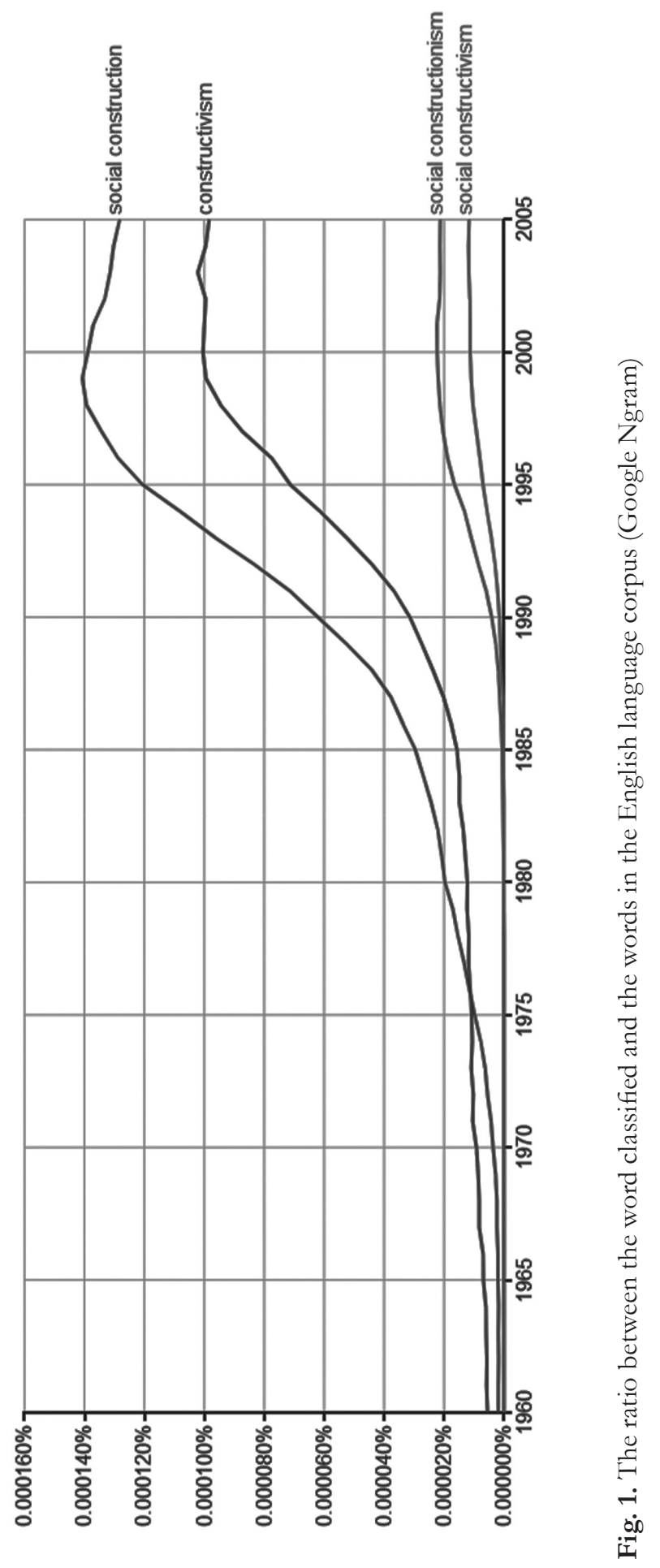

STANRZECZY 2[11]/2016 / / 211 
structivism back to Kant, stressing that the notion of social construction does not add anything "substantial" to constructivism. Before that, Bruno Latour, and Steve Woolgar (1986) had already found quite some approval when they decided not to use the term "social construction" in the title of their groundbreaking ethnography of a biochemical laboratory, which they changed from Social Construction of Scientific Facts into Construction of Scientific Facts. Latour and Woolgar argued that every construction is a social construction, so one may delete the adjective "social". But is constructivism in fact the same as social constructivism?

In order to answer this question, it may be helpful to look at the mere usage of the word provided by Google $\mathrm{Ngram}^{3}$. This corpus contains 5.2 million entries (in 7 languages, covering the years from 1800-2008). As the diagram (see Fig. 1) shows, social construction was hardly present in books before the 1960s. The use of the phrase "social construction" exhibits a slow rise, doubling about every five years, from the late 1960s up to the mid-1980s when it suddenly rises steeply. In 1998 it is 3.5 as high as in 1987. Since then its usage has been in slow decline (at least in British English - in American English it still seems to be on the rise).

Turning to related terms, note that constructivism had been more common before 1975, a fact we shall return to later. Quite obviously, the phrase "social construction" slowly takes off in the 1960s and then increases almost exponentially in the 1980s when "social constructivism" and "social constructionism" enter the scene.

Of course, constructivism emerged in the 1920s, quite evidently in relation to the well-known modernist art movement. The notion of construction has been integrated into social sciences by Piaget (1950) and his American colleague Kelly in 1955. Both authors are psychologists, and this has quite clear consequences - their idea of constructivism was that the reality (or the world) is a product of the individual mind. As you know this idea has been taken up in the 1970s by Maturana (1970) and von Glasersfeld (1974). They proposed the notion of radical constructivism for a more biological version of the same concept: reality is constructed by the individual mind, yet the mind is to be understood in much more physiological terms and as an "autopoietic" process.

Social construction, on the other hand, is significantly represented only since the 1960s. The publication of The Social Construction of Reality in

\footnotetext{
${ }^{3}$ Google's Ngram viewer indicates a constant level of $0.000001-0.0000003$ (which is almost insignificant) from 1900 to the 1960s; only by around 1970 there is a significant number of occurrences of the phrase.
} 
1966 was obviously the trigger for the dissemination of the concept. However, this notion is not just temporally disjunct from constructivism. There is also a significant conceptual difference explicitly indicated by the adjective: the reality we talk about is not a construction of the individual mind; instead, it is a social construction. The difference becomes very clear, when this idea is compared to the thesis of the construction of social reality, written 30 years later by the philosopher Searle (1995). Social reality is to him, an intentionalist, just the individual mind writ large, i.e. collective intentionality. Social construction, on the other hand, refers to social processes by which reality comes about.

\section{/// So what is social construction?}

The idea of "construction" by the mind is by far not alien to Berger and Luckmann. In fact, since it is based on Husserlian phenomenology, one may even assume, as some do, that reality is constituted by consciousness. For phenomenology argues that the world, including reality, is always a world for us, and thus it depends on the processes by which we turn towards it, that is intentionality. Being students of Alfred Schütz, Berger and Luckmann indeed start from this assumption. However, we never encounter reality per se. Even when talking or writing, I am using language which is a social institution bestowing meaning on reality independently of my will. Language and, more generally, knowledge is already existent before I start to think about reality. It is for this reason that Berger and Luckmann called their book The Social Construction of Reality - A Treatise in the Sociology of Knowledge.

Because of this focus on knowledge and because of the relevance of the book to the sociology of knowledge, we must ask whether the process by which social construction is performed and accomplished consists of "meaning". Does it just concern the social construction of knowledge? As common as this view may be, it is quite inadequate. To Berger and Luckmann knowledge is utterly important, yet they stress it, because it is guiding "conduct". This idea of knowledge guiding conduct is derived from Weber's theory of action. As action is defined by its meaning, so knowledge (as socially conventionalized meaning) is defining action. Berger and Luckmann go even further: it is not only the individual action which is constructing reality. It is, rather, social interaction which defines the basic process of social construction. Berger and Luckmann draw on "symbolic interactionism". Similarly Garfinkel's ethnomethodology (1967) is founded 
on the idea that it is by way of the members' understandings and their concerted activities that reality comes about. While Garfinkel only allows for social construction in situations, Berger and Luckmann go beyond that and analyse how reality becomes "institutionalized" and turns into a socially "objective" reality. Institutions are developed through coordinated interactions - in a way Giddens (1984) would later call the "duality of structure". Institutions differ from mere practice by the fact that they can be handed over to others: once action problems are solved interactively by coordinated actions, they may be adapted by "third parties" and reproduced without the need to redo the whole process of their construction. It is this handing-over, or, to use the term of Weber, "tradition", which turns interaction into an institution. And since this way the meaning and even the function of an institution become implicit (or "black boxed"), actors may need to try to make sense of these institutions to justify, to maintain or to change and abolish them. This making sense is what Berger and Luckmann call legitimation.

At this point "social construction of reality" arrives at a notion of objectivity which is directly related to Durkheim's ideas of social facts and institutions. Yet, while Durkheim starts from the assumption that social facts exist, the theory of the social construction of reality explains how these social facts come into existence through processes of social action and interaction. Moreover, the theory of social construction states that social reality is not just objective but becomes "internalized" or, in the new manner of speaking, "subjectified": institutions are learned and their legitimation is adopted as meaning, e.g. knowledge is acquired in such a way that it becomes part of the subjective stock of knowledge. Keep in mind that this process, again, occurs by way of interaction. Individuals internalize knowledge through socialization. It is, in the new manner of speaking, the socially "enacted" knowledge which turns the subject into a member of society or, as Berger and Luckmann call it, a "personal identity". Following Mead (1956), personal identity is not the authentic, the romantic self or the "I" - it is formed by society to such a degree that identities differ systematically with social structures.

\section{/// Critics, misconceptions: SCR as basis of CoCo}

Quite obviously, The Social Construction of Reality had anticipated the solution to a problem, which Bourdieu (1980) and Giddens (1984) would later address as the gap between subjectivity and objectivity. The significance 


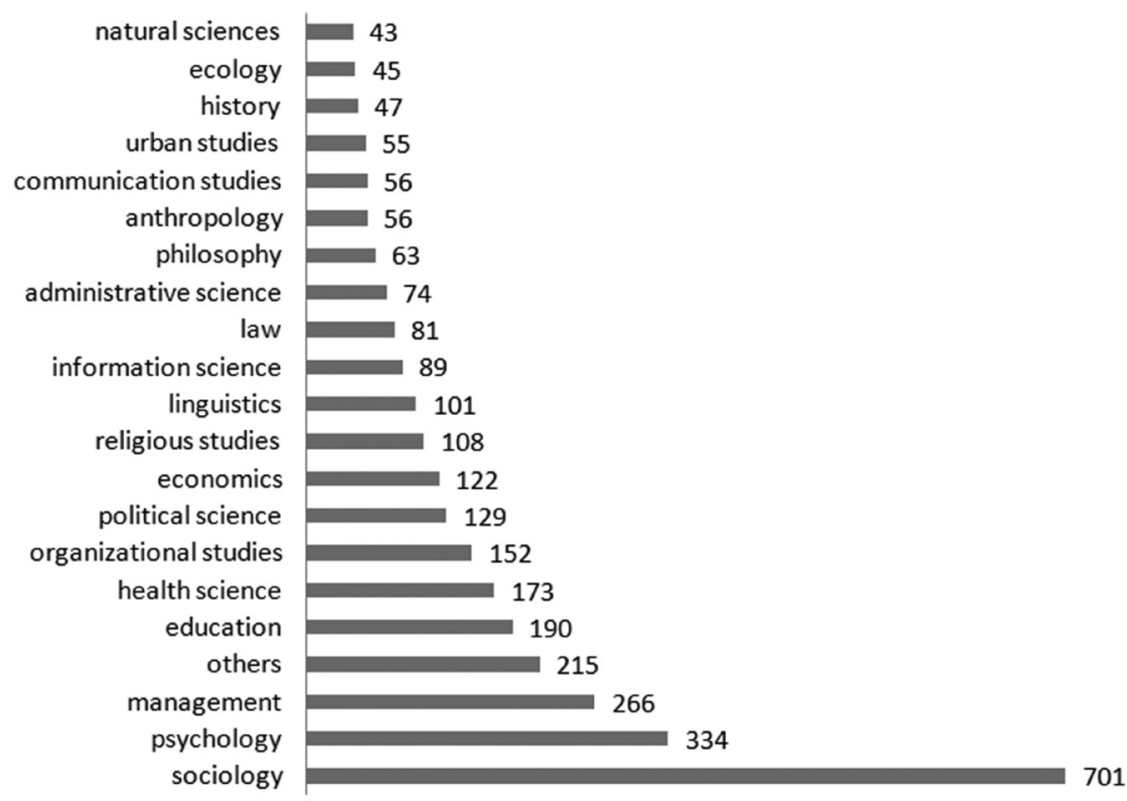

Fig. 2. Articles referring to SCR by disciplines

(Web of Science 1966-2015; N= 3100)

of this solution becomes clear when one looks at the dissemination of the book (see Fig. 2). In the 1970s the idea slowly diffused and since the 1980s various movements have been founded on it, just to mention social constructionism, which has since produced various introductions and handbooks (Burr 1995, Holstein, Gubrium 2008).

As the diagram shows, social construction exhibits signs of diffusion in a broad range of various disciplines, including the social sciences, the humanities, and even the (natural) sciences. While the concept was being disseminated, it was also transformed by different movements, such as social constructionism (Gergen 1985), which integrated into it Foucault and poststructuralism in such a way as to eliminate the subject.

Hacking (1999) has observed that the concept of social construction had been adapted, translated and even misconceived. We may surmise that as a general rule the reference to The Social Construction of Reality was ignored and the further one moved away from disciplines familiar with sociological theory to other subfields of sociology and then to completely different disciplines, the more the notion of social construction was being turned into a mere formula. In the humanities, the reference to The Social Construction is often lost and the word is subject to rather idiosyncratic interpretations 
and misunderstandings. Such confusion is quite consequential, especially because misconceptions in science often lead to tangible effects. In the matter of social construction these misunderstandings have led to new academic movements, such as post-constructivism or new realism. As I want to indicate here quickly with respect to Latour's (2010) criticism of what he considers to be constructivism or social constructivism, some of their basic arguments fall prey to a superficial understanding of The Social Construction of Reality. A sketch of the counterarguments might show why we need to move towards the idea of the communicative construction of reality, a concept which, of course, builds on an interpretation of its predecessor, The Social Construction of Reality.

1. Like Bourdieu before him, Latour criticizes the fact that "(social) construction" was cognitivist in a reductionist manner. Given the phenomenological background of social construction, this argument is in various ways wrong. First of all, SCR builds on Schütz and Luckmann's (1989) famous theory of the life-world, i.e. the kind of reality which is implicit, tacit, and taken for granted. Secondly, this life-world is understood as embodied and as starting, to use the term of German phenomenology adapted by Merleau-Ponty, from the Leib (the body as perceived subjectively).

2. Latour has also been exaggerating when he claimed that sociology had only considered humans as actors, which allowed him to announce his thesis of non-human actors as an innovation. In fact, as early as in 1970 Luckmann had written that in the social life-world almost anything can be considered as an actor - a thesis which, for example in the sociology of religion, is quite common.

3. The thesis of the life-world also hints at another misunderstanding: although reality is socially constructed, it is far from being arbitrary. Social construction is not, as new realism argues, relativist. Inasmuch as social reality becomes institutionalized, it constitutes what Durkheim has called an "objective" reality. Furthermore, this objective reality serves as a "socio-historic a priori" (Luckmann 1979) to every subsequent social construction. To put it simply: although we are always constructing reality, we do so in a world which is already constructed, and, by the way, often in forms which are also the result of social constructions.

4. This leads to another argument put forward by Latour (2010). He argues that "(social) constructivism" is caught in the paradoxes of the subject-object-hiatus common to modern philosophy since 
Descartes. To me this claim seems to be missing the most essential contribution of The Social Construction of Reality - the idea of the dialectic between subjective and objective reality. This dialectic cannot be reduced to an individual subject facing the world; rather it is by way of the interaction between (at least) two subjects that social reality is constructed. In fact, social reality is the result of this very interaction, therefore one must realize that social construction is not so much based on the relation between the subject and an object; instead it is based on the relation between the subject and another subject co-producing social reality. Or, to frame it in a different way: social construction is essentially relational.

\section{/// The communicative construction of reality}

The claim that social construction is basically relational quite obviously challenges the understanding of this theory by Berger and Luckmann themselves. However, one has to realize that, due to the unwanted kind of reception that their book received, Berger und Luckmann did not really elaborate much on the theory of social construction after the 1970s. While other approaches, such as social constructionism, adapted the concept to the theoretical challenges of the 1980s and 1990s, there have hardly been any updates in response to the more recent criticism, such as the doubts referred to by Latour.

However, over time the notion of social construction has been related to a huge number of empirical studies, which were involved in the development of a range of new methods (mostly qualitative), such as social scientific hermeneutics, the sociology of knowledge approach to discourse analysis, ethnosemantics, communicative genre analysis or videography. All these methodical perspectives exhibit a tendency to shift from what used to be the linguistic turn to what may now be called a communicative turn (Knoblauch 1995). It is noteworthy that while the above-mentioned studies were in the process of turning to communication in terms of methods and empirical studies, there have been some other attempts to rebase social theory on communication (maybe after recalling that communication was the basic theory for Cooley and Mead). These efforts were undertaken in Germany, for example by Habermas and by Luhmann. The notion of communicative construction reflects these changes, and marks the adjustments made to social construction. 
For the modifications to become clear immediately it's enough to start with considering the role of relationality mentioned above. To Berger and Luckmann the very possibility of analysing the social construction of reality while also being involved in this process depends on an analysis of the precondition for construction in the subject. The analysis of subjective consciousness, as suggested by phenomenology, provides to them the starting ground for every scientific analysis. If, however, we follow their own theory of identity as formulated in The Social Construction of Reality, we realize that the phenomenological subject with which they start must be a historically situated and socially constructed "personal identity"; and in fact, the analysis cannot refute the perspectivity of its authors, i.e. of modern white, self-reflective and very verbal western beings. Relationality, therefore, not only accounts for the fact that subjects are always part of social relations; it also sets the subjective perspective within a "relation", in the sense which Mannheim (1936) has called "relationing". Therefore, relationality illuminates the fact that the epistemological subject is always socialized, even before it starts to know, and that knowledge depends on us being social.

This notion of relationality distinguishes itself from individualistic notions of action, knowledge and practice by not taking the relation between the subject and the world as its basis. Yet it also differs from most relationist theories in sociology in the sense that it does not consider relations as static but instead as processes. Relations are made up of actions and practices by which they are constituted. Moreover, as communicative constructivism adds, these processes are not just bivalent, i.e. relations only between one subject and another subject. They include an objectivation which allows for the incorporation of the material reality into the relation. Communicative action is the social action relating subjects to an objectivation.

Objectivation as a category has already been suggested by Berger and Luckmann. As in many other theories of communication (such as Habermas' theory of communicative action or Gergen's stress on discourse), their concept too was focused only on language as the most decisive form of objectification of meaning. The notion of objectification, however, allows bodily conduct to be included in the concept of social reality. One notable example is the finger pointing, which to Tomasello (2008) constitutes ontologically as well as phylogenetically the most basic method of identifying signification. One should add that in a very fundamental way it is a conditio bumana because pointing is one of the most significative gestures humans acquire in the ninth month of their life; it is not exclusive to humans though - it can be learned, e.g., by chimpanzees. It is characterized by a reciprocal 
orientation, as opposed to the mere coordination of egoistic actions. Since it is also connected to an objectification which takes on meaning, we would call it a communicative action.

Although the term communicative action had been used by Schütz, it was coined by Habermas (1985). Habermas stresses the importance of communication to the role of language seen as the kernel of communicative rationality, and he distinguishes it from instrumental action. It has been argued that in this way Habermas ignores the function of materiality, e.g. the voice or the written word. Yet logical thinking, as we know, is dependent less on spoken language than on the invention of writing. Our notion of communicative action, e.g. pointing, avoids the basic distinction of the two different action types. By considering communicative action as an embodied performance relating to an objectification, the concept also allows us to take into account the role of materiality in social reality, for instance the role of objects, technologies and media ${ }^{4}$.

\section{/// Communication society and communicative rationality}

So far this sketch has mainly dealt with theoretical questions as well as methods, as if they followed an internal logic. However, sociology too forms part of society. Society is not only the subject matter of sociology, but also its major condition. The movement from the social to the communicative construction of reality, thence, is also a result and a consequence of the transformation of society into what I would call the communication society. As this transformation has not been elaborated on before, I would like to at least indicate the essential aspects of this type of society.

Although modern society has been variously said to be transformed by deindustrialization, post-Fordism or cultural globalization, these changes only relate to certain institutional spheres of society, particularly economy, culture and politics (which were assumed by postmodernists to have lost their dominant role). The notion of a communication society, however, hints at a change which affects all spheres of society. Communication, which used to be restricted to culture or the "media system", takes on a new role. It becomes productive in a material sense by enabling us to create things (as in 3D printing) which contribute to the dissolution of the distinction between the consumer and the producer. It transforms politics

${ }^{4}$ For a more detailed elaboration of communicative constructivism in English cf. Knoblauch 2013. A book on the theory (Kommunikative Konstruktion der Wirklichkeit) has been published in 2017 in Wiesbaden in German. 
(into "post-democracy"), religion (into "popular religion") and even affects everyday life: social relations become mediated in a way which now makes it impossible to tell the difference between the "real" and the "virtual".

The transformation into a communication society is based on the construction of large technical infrastructures, e.g. the "informatization" starting in the 1960s and 1970s. These infrastructures are not neutral but form part of the social structure in that they provide the basis for social relations, networks and communities in terms of inclusion as well as in terms of exclusion. Their particular impact is due to the digitization of technology, which means that technological processes have been adjusted to digital sign systems and programs. This way, as technology became basically significative and communicative, the inter- and intra-activation has linked it to human actors in a manner which makes it increasingly difficult to tell who is acting and who is not. This is a common problem of all institutions, yet quite new to their technological and infrastructural versions. Even if these systems become active themselves, following their own algorithms, being interconnected in a "smart" way and using "big data", they are still formed by communicative actions in which meanings and ideas have been inscribed.

This changing role of communication and the materiality of communicative action raise the question of whether something like "communicative rationality" still exists. Are we subject to the instrumental rationality inscribed into technologies or do we need a communicative rationality enshrined in the dialogical use of language (as Habermas had suggested)? Although we have dethroned language in our notion of communicative action, we haven't lost ourselves in plain relativity. Habermas' contrafactual assumption that in addressing others we implicitly assume to be understood by them rests on one basic principle. It is the principle of reciprocity, which lies at the basis of every communicative action. True, this rule is not restricted to humans, and it may include chimpanzees, probably even robots, but it does, in a rather asymmetrical way, presupposes the participation of humans or what we might call humanity. Yet, even if we need to assume that communicative rationality applies to humans, we must, following Habermas, ask, whether there is anything left of truth, if it is not guaranteed by language as the instrument of reason. In fact, the intrusion of visualization, e.g. PowerPoint, into science makes it very clear that even scientific truth is dependent on perspectives, on bodies, their senses and their movement, and of course, on technologies. 
However, although we know that science is a social and a communicative construction, we should remember that social constructions can and do become historic institutions, made up of discourses on truth, experiences, methods and reality. Despite the fact that some fear, with Foucault, that the truth of science lies only in its social and discursive power, it is my belief that the creation, diffusion and reception of science always demands that we perform communicative actions together but also alone, for example thinking. (In fact, it seems to me, that this is what I am doing right now, at least when writing this paper). Although our communicative acts rarely, or probably never lead to truth, truth as a social construction has always been quite consequential. It is not just a legitimatory principle but a directive idea in our communicative actions - at least inasmuch and when we do science. And it seems that we can quite reasonably communicate on the basis of this simple assumption of truth. On the basis of this belief we have achieved quite a reasonable consensus as to the words, the methods and the experiences we share in order to achieve truth. Moreover, we know that we can never achieve truth (and might not even come closer to it, as Popper assumed), therefore we go on communicating about it. This is what makes up sociology, science and (though it probably concerns the belief in truth less than other matters) society.

Bibliography:

/// Berger P.L., Luckmann Th. 1966. The Social Construction of Reality. A Treatise in the Sociology of Knowledge, Free Press New York.

/// Bourdieu P. 1980. Le sens pratique, Editions Minuit.

/// Burr V. 1995. An Introduction to Social Constructionism, Routledge.

/// Gergen K.J. 1985. The Social Constructionist Movement in Modern Psychology, „American Psychologist”, vol. 40(3), pp. 266-275.

/// Giddens A. 1984. The Constitution of Society: Outline of a Theory of Structuration, Polity.

/// Glasersfeld E. 1974. Piaget and the Radical Constructivist Epistemology, [in:] Epistemology and Education, eds. C.D. Smock, E. Glasersfeld, Follow Through Publications, pp. 1-24.

/// Habermas J. 1985. The Theory of Communicative Action, Beacon Press. 
/// Hacking I. 1999. The Social Construction of What?, Harvard University Press.

/// Hałas E. 2010. Towards the World Culture Society. Florian Znaniecki's Culturalism, Lang.

/// Holstein J.A., Gubrium J.F., eds. 2008. Handbook of Constructionist Research, The Guilford Press.

/// Kelly G.A. 1955. The Psychology of Personal Constructs, Norton.

/// Knoblauch H. 1995. Kommunikationskultur. Die kommunikative Konstruktion kultureller Kontexte, De Gruyter.

/// Knoblauch H. 2005. Wissenssoziologie, UVK Verlagsgesellschaft.

/// Knoblauch H. 2013. Communicative Constructivism and Mediatization, „Communication Theory”, vol. 23(3), pp. 297-315.

/// Knoblauch H. 2016. Communicative Constructivism and the Communication Society, [in:] Life-World, Intersubjectivity and Culture. Contemporary Dilemmas, ed. E. Hałas, Lang, pp. 185-200.

/// Knoblauch H. 2017. Die kommunikative Konstruktion der Wirklichkeit, Springer.

/// Knoblauch H., Wilke R. 2016. The Common Denominator: The Reception and Impact of Berger and Luckmann's The Social Construction of Reality, „Human Studies", vol. 39(1), pp. 51-69.

/// Latour B. 2010. On the Cult of the Factish Gods, [in:] On the Modern Cult of the Factish Gods, ed. B. Latour, Duke University Press, pp. 1-67.

/// Latour B., Woolgar S. 1986. Laboratory Life. The Anthropology of Scientific Facts, Princeton University Press.

/// Luckmann Th. 1970. On the Boundaries of the Social World, [in:] Phenomenology and Social Reality. Essays in Memory of Alfred Schutz, ed. Maurice Natanson, The Hague, pp. 73-100.

/// Luckmann T. 1972. The Constitution of Language in the World of Everyday Life, [in:] Life-world and Consciousness: Essays for Aron Gurwitsch, eds. L.E. Embree, A. Gurwitsch, Northwestern University Press, pp. 469-488.

/// Luckmann T. 1979. Personal Identity as an Evolutionary and Historical Problem, [in:] Human Ethology: Claims and Limits of a New Discipline, eds. M. von 
Cranach, K. Foppa, W. Lepenies, D. Ploog, Cambridge University Press, pp. 56-74.

/// Lynch M. 1998. Towards a constructivist genealogy of social constructivism, [in:] The Politics of Constructionism, eds. I. Velody, R. Williams, Sage, pp. 13-32.

/// Mannheim K. 1936. Ideology and Utopia, Routledge.

/// Maturana H.R. 1970. Biology of Cognition. Biological Computer Laboratory Research Report, Biological Computer Laboratory, Department of Electrical Engineering, University of Illinois.

/// Mead G.H. 1956. On Social Psychology, University of Chicago Press.

/// Piaget J. 1950. La construction du réel chez l'enfant, Delachaux et Niestlé.

/// Schütz A., Luckmann T. 1989. The Structures of the Life-World II, Northwestern University Press.

/// Searle J.R. 1995. The Construction of Social Reality, Free Press.

/// Tomasello M. 2008. Origins of Human Communication, MIT Press.

/// Znaniecki F. 1975. The Social Role of the Man of Knowledge, Octagon Press. 